\title{
EL 'REALISMO MÁGICO’: UNA CATEGORÍA CRÍTICA NECESITADA DE REVISIÓN
}

\begin{abstract}
José Carlos GONZÁLEZ BOIXO
Universidad de León carlos.boixo@unileon.es

L a historia del 'realismo mágico' no deja de hacer honor a su inicial carácter oximorónico, desde que Franz Roh ${ }^{1}$ utilizase dicha expresión en 1925 para definir una tendencia pictórica contraria al expresionismo. No falta, pues, demasiado tiempo para que pueda celebrarse su centenario y su esencia paradójica se ha perpetuado a lo largo de los años, sin que escritores, críticos y lectores hayan podido alcanzar un consenso sobre el misterioso significado que se oculta tras tan sugerente denominación. Babélica quimera levantada por la crítica académica, sigue alzándose sin que el paso del tiempo vea su culminación, colonizando nuevos territorios y necesitada, siempre, de una urgente definición que permita, en cada momento, establecer unos referentes comunes entre los participantes que se aventuran al análisis de tan procelosa categoría crítica. No solo resulta

\footnotetext{
${ }^{1}$ El término 'realismo mágico' figuraba en el título del libro que publicó en alemán en ese año. La traducción del texto de Roh, realizada por Fernando Vela, apareció inicialmente como artículo, con el título «Realismo mágico. Problemas de la pintura europea más reciente», Revista de Occidente, año V, nº XLVIII (Madrid, junio de 1927), pp. 274-301. Se trata de una versión reducida del libro que ese mismo año publicó la editorial Revista de Occidente (ignoro la razón por la que en las bibliografías siempre aparece la fecha de 1928) con el título en portada de realismo mágico (en grandes caracteres) y, en línea más abajo, post expresionismo (en un tamaño de letra sensiblemente menor. En página 7, al repetir el título, se añade en un tipo de letra menor que los anteriores Problemas de la pintura europea más reciente. Estas diferencias tipográficas tienen gran interés porque ponen de manifiesto el interés por destacar el término 'realismo mágico', nombre atractivo si se quería postular una nueva teoría e, indudablemente, desde un punto de vista comercial. Esta doble publicación garantiza su conocimiento en el ámbito hispánico, pero no hay constancia de que la teoría de Roh ejerciese alguna influencia ni en Uslar Pietri ni en Carpentier cuando ambos crean, en 1948 y 1949, una teoría sobre el 'realismo mágico' aplicado a las letras hispanoamericanas (Carpentier, con la denominación 'lo real maravilloso'). La referencia a Roh debe limitarse a un simple origen etimológico (tal como señala Llarena, 1997: 24). El título parece una decisión de última hora, ya que en todo el texto solo en tres ocasiones se utiliza el término 'realismo mágico' que es sustituido de manera habitual por la fórmula 'la pintura más reciente' o por 'post expresionismo'; es decir, lo que se conoció en la pintura alemana como 'Nueva objetividad'. Nos movemos, pues, en el campo de la pintura, lo que no representaría un mayor inconveniente en lo relativo al concepto de 'realismo mágico', si no fuese porque los sinónimos que emplea, en su disparidad, nos deben poner en alerta. Lamentablemente estamos condicionados por el título del libro, como si Roh hubiese pretendido hacer una teoría consecuente con el mismo, y no nos percatamos de que no es así, ya que lo que pretende es identificar una serie de corrientes diversas, incluso muy diferentes entre sí, que, caracterizadas por la vuelta al realismo (aunque insistirá que se trata de un realismo diferente al del siglo XIX), se oponen a la abstracción de diversos movimientos pictóricos de comienzos del siglo $\mathrm{XX}$. Todo ello nada tiene que ver con los posibles significados asignados en las últimas décadas al término 'realismo mágico'.
} 
extremadamente complejo tratar de ofrecer una definición precisa — aunque es fácil dar una definición simple que se mostrará en seguida ineficaz, en el momento en el que se le aplique una mínima profundización - sino que, desde la perspectiva actual, se observa una multiplicidad de significados que son fruto de enfoques temporales. Llegados a este punto, la fragilidad del término 'realismo mágico' se muestra en toda su amplitud. Quien lo utilice debe tener en cuenta el factor temporal y considerar los diversos significados que en cada momento ha tenido. Pero, además, puesto que dicha categoría crítica sigue teniendo plena vigencia, tendrá que seleccionar entre sus varias significaciones actuales la que considera adecuada al análisis de la obra artística ${ }^{2}$, tanto si se trata de una obra contemporánea, como si se refiere a una obra del pasado. En este último caso será imprescindible tener presente una perspectiva historicista en el análisis, aunque dicho enfoque resultará insuficiente si se pretende aplicar la categoría «realismo mágico» como concepto crítico actual.

Uno de los errores de la crítica ha sido la consideración del desarrollo de la teoría del realismo mágico como un continuum temporal en el que la ordenación cronológica de las contribuciones críticas mostraría la evolución del proceso de teorización. En principio, parece razonable esperar que una aportación que fuese precedente a otra ejerciese su influjo en la siguiente y, así, sucesivamente. De este modo, los teóricos del realismo mágico inician su origen en Franz Roh (1925), al que seguiría Bontempelli $(1926)^{3}$, luego el término pasaría a América volviendo a aparecer en 1948 con Uslar Pietri, siendo significativas en el proceso de consolidación del término las fechas de 1955 (Ángel Flores), 1967 (Luis Leal) y 1975 (Congreso del IILI que dedicó una sección a la cuestión; Yates, 1975). A partir de esta fecha las aportaciones críticas se multiplican, diversificando los sentidos de una categoría que puede considerarse consolidada. La formación del concepto del realismo mágico a través de sucesivas aportaciones críticas a lo largo del tiempo parecería lo razonable, pero, en realidad, se trató de un proceso en el que la discontinuidad cronológica es el elemento fundamental para llegar a comprender el término. Al aplicarse a una multitud de realidades resultó necesaria una constante redefinición, ligada a un determinado momento cronológico, pero que no está predeterminada por el uso previo del término. En buena medida se trata de un proceso lleno de paradojas en el que tanto los críticos como los lectores pueden perderse. Lo fundamental resultará, pues, establecer los núcleos desde los que el término cobra fuerza, desechando la ficticia progresión cronológica.

La categoría literaria 'realismo mágico' ha resultado ser, pues, un concepto complejo, difuso y ambiguo, cuya utilidad ya era puesta en duda en 1975 por Rodríguez Monegal ${ }^{4}$. Solo recientemente se han llegado a consensuar, desde el campo de la teoría literaria, unas características básicas que permitirían una definición estable. Sin embargo, lejos de haberse llegado a una solución, el problema se agrava, dado que esa definición sitúa el concepto de 'realismo mágico' en el campo abstracto e

\footnotetext{
${ }^{2}$ Hoy en día se habla de realismo mágico en literatura, artes pláticas y cine. Incluso el término se ha generalizado tanto que se ha convertido en imagen habitual en cualquier ámbito social.

${ }^{3}$ Bontempelli empezará a emplear el término 'realismo mágico' en la revista 900, que él mismo dirigirá, en su primer número (otoño de 1926). Se refiere de manera genérica a la transformación de la realidad por la aparición de elementos fantásticos.

${ }^{4}$ Su crítica es muy dura y la expone en la sesión inaugural del XVI Congreso del Instituto Internacional de Literatura Iberoamericana que trató especialmente esta cuestión (Yates, 1975).
} 
intemporal de las técnicas narrativas, como si fuese un recurso más de las corrientes de 'lo insólito' (la literatura no realista), disponible para su uso por cualquier escritor actual. Al contrario, la posición que aquí se mantiene es que el 'realismo mágico' fue una tendencia de la literatura hispanoamericana, casi siempre ligada a su narrativa, con unos orígenes bastante definidos (inicios de los años treinta del siglo XX) fundamentados en cuestiones ideológicas, que alcanza su plenitud en Cien años de soledad (1967) de García Márquez, novela en la que, aunque permanece el sustrato ideológico, el 'realismo mágico' se convierte en una técnica narrativa (la que se corresponde con la definición de los teóricos actuales) y que, después de su éxito fulgurante en los años setenta (coincidiendo y, muchas veces, identificada con la nueva narrativa del 'boom' hispanoamericano) tiene sus últimos adeptos en la década de los ochenta, y terminaría siendo denostada por los escritores hispanoamericanos que toman el relevo en los años noventa. Desde esta posición reduccionista del término 'realismo mágico' (solo estableciendo límites precisos tiene relevancia crítica) puede afirmarse que dicha tendencia ha desaparecido de las letras hispanoamericanas desde hace más de dos décadas.

La mayor parte de las confusiones que se siguen produciendo en la conceptualización del término ‘realismo mágico' derivan de la no distinción entre esa doble tipología ya anunciada. De hecho, es imprescindible distinguir entre el 'realismo mágico' de tipo ontológico (aquel que nace como expresión de una ideología) y el 'realismo mágico' de tipo técnico (el uso de una fórmula narrativa desvinculada de un tema determinado). En el ámbito de la literatura hispanoamericana se puede trazar con nitidez su evolución desde sus orígenes ideológicos (expresión del pensamiento mítico-mágico propio de las culturas indígenas), la formulación de una teoría (una realidad oculta de América de carácter utópico) que Uslar Pietri denominaría 'realismo mágico' en 1948 y Carpentier 'lo real maravilloso' en 1949 (en su introducción a El reino de este mundo, luego ampliada en 1967), hasta su conversión en 'técnica' por García Márquez en 1967. Este proceso es bastante preciso, por lo que el término 'realismo mágico' puede ser definido con nitidez, siempre que se tengan en cuenta sus dos acepciones, ontológica y técnica. Sin embargo, desde que el término empieza a aparecer en la crítica literaria desde los años cincuenta, resulta llamativa la variedad de significados que presenta, de manera que ha sido constante su redefinición ${ }^{5}$. El éxito del término estuvo ligado al reconocimiento que a partir de los años sesenta tuvo la narrativa hispanoamericana, hasta el punto de que varios críticos (y, sin duda, muchos más lectores) consideraron equivalentes los términos 'realismo mágico' y 'nueva narrativa hispanoamericana' o 'narrativa del boom', algo que, además de erróneo, vacía de contenido al concepto de 'realismo mágico'. Por otro lado, la inicial identificación del 'realismo mágico' con la literatura 'fantástica' (Ángel Flores lo hace ya en 1955) ha pervivido hasta la actualidad, siendo esta la más nociva de las interpretaciones, ya que es capaz de situar en un mismo plano a autores que, como Borges o Cortázar, nada tienen que ver, en este aspecto, con Asturias o García Márquez (si los críticos llegan a estas confusiones, es fácil imaginar la desorientación de los lectores normales al enfrentarse al concepto de 'realismo mágico'). Han sido este tipo de interpretaciones generalistas las que han

\footnotetext{
${ }^{5}$ Llarena (1997: 21-66) hace un minucioso recorrido de la crítica al respecto.
} 
sumido al término en una ambigüedad que lo convierten en confuso y, en consecuencia, lo invalidan como concepto crítico.

Habría que pensar que el término resultó atractivo desde que empezó a usarse, única explicación factible cuando se constata su proliferación. No ha resultado fácil para la crítica más avisada imponerse entre esa maraña de imprecisiones. Si, por una parte, el 'realismo mágico' ontológico podía definirse con nitidez a partir de las formulaciones de Uslar Pietri y Carpentier, más complejo resultaba incluir la práctica que del mismo podía observarse en García Márquez, punto sin retorno de una nueva concepción del ‘realismo mágico’ basado en la técnica. Resultó así que las definiciones de la crítica más solvente, a partir de 1967, obviaron el componente ontológico que el término había tenido hasta entonces y se decantaron por el componente técnico. Se trató de definir el curioso proceso de mezcla de realidad y fantasía que se producía en Cien años de soledad, novela modélica e indiscutible del ‘realismo mágico', llegándose a la conclusión de que se trataba de la invención de una técnica que se situaba en el ámbito de la literatura de lo ‘insólito' (forma genérica de la literatura no mimética), pero claramente diferenciada de la literatura 'fantástica' y de la literatura 'maravillosa'. Al no ser factible la homologación de las tendencias ontológica y técnica en el 'realismo mágico', se toma como modelo esta última y se margina la ontológica a un momento dado del proceso histórico. Lo que parece ser una solución al eterno problema de la definición del 'realismo mágico' al convertir en categoría universal una técnica que compite con otras (realismo, lo fantástico, lo maravilloso) en el plano de la teoría, es, sin embargo, una falsa salida, ya que el 'realismo mágico' no puede comprenderse fuera de su contexto histórico en el marco de la literatura hispanoamericana. Entraron así en conflicto concepciones distintas del 'realismo mágico': las que, de modo poco preciso, se correspondían al periodo anterior a 1967 y para las que era suficiente la mezcla de lo real y lo fantástico, y las posteriores a esa fecha que delimitarían la técnica a partir de la novela de García Márquez. En resumen, tres concepciones del 'realismo mágico' se han venido desarrollando desde que el término apareció en 1948, aplicado a la narrativa hispanoamericana: una de tipo generalista, en la que el 'realismo mágico' se confunde con la narrativa de 'lo fantástico'; otra de tipo ontológico, que sería expresión del pensamiento mítico de las culturas indígenas (lo que Carpentier denomina 'lo real maravilloso'); y la última, de tipo técnico, una fórmula narrativa que se inscribe en el marco teórico de la literatura de 'lo insólito' y que no necesita justificarse en valores ideológicos. Es un hecho constatable que el 'realismo mágico' se convierte en una etiqueta crítica de éxito a partir de su aplicación, en torno a los años sesenta, a la narrativa hispanoamericana, con la que en un momento dado llega, incluso —aunque equivocadamente-, a identificarse. La utilización del término en los años veinte por Roh o Bontempelli no tuvo mayor eco, ni tampoco la ocasional aparición en años sucesivos, sobre todo en el campo de la pintura. Es, pues, la relación 'realismo mágico - narrativa hispanoamericana el núcleo del que debe partir el estudio de esta tendencia o género, tanto para analizar sus preliminares, como para tener una perspectiva correcta de su pervivencia posterior a los años noventa, cuando puede decirse que desaparece de la narrativa hispanoamericana, y, sin embargo, adquiere una notable difusión en otras literaturas y manifestaciones artísticas ajenas al ámbito hispanoamericano. 
Hoy es posible trazar con bastante exactitud cuál fue el origen, desarrollo y final del 'realismo mágico' en la literatura hispanoamericana. Lo paradójico del caso es su 'renacimiento' y su multiplicación en otros ámbitos literarios, su aplicación a otras artes y su uso generalizado, de tal manera que se ha convertido en slogan publicitario y en expresión tópica ${ }^{6}$. La aceptación, en el marco de la teoría literaria, de una definición técnica del 'realismo mágico' poco significa ante lo que podría calificarse de un virus incontrolable que pone de manifiesto el éxito actual de la expresión, pero que, al mismo tiempo, difumina su significado que, como en sus orígenes, remite a una vaga concepción de un arte en el que se entremezclan los elementos reales y fantásticos. El abusivo uso de la expresión puede observarse en los casos que se citan a continuación, y la consecuencia es que en la mayoría de los casos no aporta ningún valor crítico e, incluso, puede ser motivo de confusión. En el caso de la literatura la expresión alcanza al conjunto de las literaturas mundiales y suele reconocerse la influencia del modelo hispanoamericano. El ámbito de aplicación tiende a ser el mundo rural, las sociedades no industrializadas, espacios marginales, desde la teoría de género, proyección de las teorías postcoloniales y el tercer mundo. Algunos ejemplos: el estudio comparativo de Noriega Sánchez (2002) sobre el 'realismo mágico' en la literatura de mujeres contemporáneas afroamericanas, indígenas americanas, chicanas y mexicanas; en el conjunto de ensayos editados por Parkison y Faris (1995) puede observarse la generalización del 'realismo mágico' en literaturas de Asia, África, Europa, USA, Canadá y Australia ${ }^{7}$, algo que también se aprecia en Menton (1998) y en Schell (2005); del mismo modo, Chanady (1985) lo constata en el escritor canadiense Jacques Ferron (que reflejaría sus experiencias de médico rural), y, sin duda, el ámbito geográfico en el que más ha prosperado fuera de Hispanoamérica la categoría de ‘realismo mágico' es África, donde estaría representado por escritores como Mia Couto, Alain Mabanckou, Moses Isegawa y Ben Okri ${ }^{8}$. Si en el caso de estos ejemplos en el género de la narrativa ya resulta difícil la semejanza con los modelos hispanoamericanos, la generalización del uso del término 'realismo mágico' a otros campos, lejos de establecer una categoría conceptual, termina siendo motivo de confusión. Algo en lo que coincide Camayd Freixas:

\footnotetext{
${ }^{6}$ Un ejemplo puede ser la campaña publicitaria iniciada por el Gobierno colombiano en 2013 bajo el lema «Colombia es realismo mágico» y continuada en Fitur (Feria Internacional de Turismo, Madrid, enero, 2014): «Lo que para nosotros puede resultar normal para un turista es una imagen mágica, un momento revelador, una experiencia inolvidable». La expresión se ha popularizado hasta el punto de convertirse en «muletilla». Por ejemplo, se podía leer en un periódico: Brasil rompe con el realismo mágico de Colombia y se citará con Alemania en semifinales (Campeonato Mundial de Fútbol, 2014).

${ }^{7}$ Este voluminoso libro (581 págs.) reúne una veintena de ensayos de diversos críticos, con una orientación, en términos amplios, que podría identificarse con una visión 'generalista' del realismo mágico. En la práctica se identifica el término con 'lo fantástico', y se proyecta su aplicación hacia las teorías postmodernas y neocolonialistas. En ese sentido, las autoras de la antología crítica consideran que representa una tendencia universal (aunque no deja de ser curioso que los autores más citados son los hispanoamericanos). La posición que aquí se mantiene difiere sustancialmente de esta perspectiva.

8 Brahim Barhoun, Magical Realism as postcolonial discourse: magic, the carnivalesque and hybridity in Ben Okri's Abiku trilogy (tesis doctoral, Universidad Complutense, 2013). Algunos de estos escritores han reconocido la influencia directa del modelo hispanoamericano. Ciertas similitudes entre Hispanoamérica y África (pervivencia de culturas indígenas no integradas en el mundo moderno) hacen aflorar muestras de un pensamiento no racional que puede reflejar tanto una realidad profunda como un exotismo caro a la cultura occidental. Algo que también se refleja en el arte africano, especialmente en la pintura.
} 
[...] cada día se utiliza más el término 'realismo mágico’ en otros contextos nacionales. En la literatura canadiense el tema tiene ya una tradición crítica; pero no se alarme quien encuentre hoy, en paseo por la biblioteca, numerosos artículos sobre el realismo mágico estadounidense, europeo, africano, ruso, japonés y — ¿por qué no? - chino (sin mencionar su aplicación al cine, a la pintura y aun a la arquitectura) (1998: xii).

Hay que admitir el atractivo del término, pero eso no justifica que, como hace el crítico César Augusto Ayuso, pueda ser empleado para definir una corriente poética española con cierta tendencia a lo fantástico ${ }^{9}$. Confusión que, de modo especial, ha encontrado un lugar predilecto en el campo de la pintura. Así resulta que René Magritte es considerado el maestro del realismo mágico, cuando es mucho más exacto decir simplemente que es surrealista. También así ha sido calificado Edward Hopper, maestro, en este caso, del hiperrealismo. Y lo mismo se señala de Rob Gonsalves, pintor canadiense de inspiración surrealista y, en concreto, daliniana ${ }^{10}$. Esta abusiva utilización de la expresión 'realismo mágico', extendida a todas las artes y a las más diversas situaciones de la vida cotidiana, apenas remite hoy a algo más que a un gesto hiperbólico de asombro ante una realidad que, al sobrepasar sus límites de cotidianidad, nos sorprende.

El panorama es, pues, complejo, pero también confuso, a pesar de los múltiples estudios que se han dedicado al tema. Independientemente de que se considere el 'realismo mágico' como una tendencia universal, de la que en un momento dado la narrativa hispanoamericana formara parte, o bien, que sea consustancial a determinada tendencia de la narrativa hispanoamericana, en ambos casos puede constatarse que la crítica literaria no ha sido capaz de consensuar una definición explícita de dicha tendencia. Hoy es posible, sin embargo, llegar a esa definición si partimos del marco teórico de la literatura de 'lo insólito': como es bien conocido, desde finales de los años cincuenta se desarrollan estudios sobre la literatura fantástica que, en buena medida, culminan con las formulaciones de Todorov en $1970^{11}$. A partir de ese momento, nuevas formulaciones han permitido establecer una serie de categorías en el ámbito de la literatura 'no mimética' (espacio en el que necesariamente ha de situarse el 'realismo mágico') que son las que deben confrontarse para poder dirimir las características específicas del movimiento o tendencia que aquí nos ocupa. Es, pues, en ese espacio teórico de 'lo insólito' donde debe buscarse una definición que sea la que permita revisar de forma retrospectiva el probable uso abusivo del término desde 1925 hasta nuestros días. De esta manera, podrán desecharse

\footnotetext{
${ }^{9}$ César Augusto Ayuso, El realismo mágico (un estilo poético de los años cincuenta), 1995.

${ }^{10} \mathrm{Ni}$ siquiera hay elementos comunes entre los tres. Hopper muestra un realismo sorprendente por su detallismo y elige motivos cotidianos, pero sin que introduzca ningún elemento fantástico. Magritte crea situaciones absurdas, de tipo onírico, al reunir elementos reales en combinaciones fantásticas (hombre cuya cabeza se sustituye por una manzana; lluvia de hombres con paraguas). Gonsalves parte de un elemento real para crear un mundo fantástico mediante un proceso de ilusión óptica (las aguas de una cascada situada al fondo del cuadro terminan, en un primer plano, convertidas en danzarinas; las cometas que surcan el cielo se convierten en barcos que surcan el mar; las olas de la playa se convierten en montañas nevadas).

${ }^{11}$ Pasos decisivos en la formulación de una teoría de lo fantástico fueron las obras de Louis Vax, L'Art et la littérature fantastique (1960), Roger Caillois, Au coeur du fantastique (1965) y, especialmente, Tzvetan Todorov, Introduction à la littérature fantastique (1970). Lo mismo que en el caso del realismo mágico, los términos 'fantástico', 'maravilloso' y equivalentes, pueden ser utilizados en un sentido 'generalista' (usos del habla comunes) y como acepciones específicas de la crítica literaria. Respecto a la literatura no mimética, David Roas (2015) establece cuatro categorías: lo fantástico, lo maravilloso, el realismo mágico y la ciencia ficción, y analiza sus efectos sobre el receptor. En lo que respecta al 'realismo mágico', Roas sigue la teoría de Chiampi (1983), de quien toma la expresión 'realismo maravilloso'. Como muchos críticos, ambos no hacen distinción entre ‘realismo mágico’ y ‘lo real maravilloso', posición que comparto.
} 
las utilizaciones inadecuadas del término, tanto aquellas que lo equiparan a 'lo fantástico', como las que, con una generalización improcedente en la crítica literaria, se limitan a identificarlo con situaciones en las que se entremezclan elementos realistas y fantásticos. Solo teniendo claro el concepto de 'realismo mágico' podrá analizarse la utilización de este término en tan dilatado espacio de tiempo, los usos indebidos y los correctos, incluidos en este caso los múltiples matices que pueden observarse, matices que siempre han de respetar la parte esencial de la definición. Alguien podría argumentar que sería más lógico trazar una teoría después de un análisis del uso del término a lo largo del tiempo. Craso error: la multiplicidad de significados que ha ido adquiriendo hace inviable buscar una síntesis que los resuma, por la sencilla razón de que el término fue utilizado de manera arbitraria por escritores y críticos, sin que existiese una teoría en la que basarse. De forma un tanto paradójica, nos vemos en la actualidad obligados a formular una teoría que ha de aplicarse de forma retrospectiva, delimitando el uso 'correcto' del término desde nuestra perspectiva, que no tiene por qué ser coincidente con el uso dado con anterioridad. Es cierto que al no existir una teoría previa que aplicar, cada autor o crítico está en su derecho de interpretar a su manera el término 'realismo mágico', pero, por ello mismo, se hace imprescindible consensuar una teoría que otorgue validez crítica al término. En conclusión, lo que aquí se propone es la elaboración de una teoría del 'realismo mágico' en el marco de la literatura de 'lo insólito' y, como paso posterior, una revisión de los momentos que pueden considerarse cruciales en el desarrollo cronológico de esta tendencia, con la finalidad de verificar su validez en relación a la teoría expuesta.

Puede parecer sencilla la definición del 'realismo mágico' que, en principio, podría responder a la siguiente proposición: la presencia de lo sobrenatural en un relato tipificado como realista, sin que este hecho provoque una reacción de extrañeza en los personajes. Es cierto que esa falta de reacción de los personajes ante la aparición de un hecho que no puede explicarse racionalmente, teniendo en cuenta que el relato tiene una base realista (convencionalmente admitida por el lector), es el elemento imprescindible que es necesario que aparezca para poder hablar de 'realismo mágico', pero es, al mismo tiempo, insuficiente en sí mismo, si no se encuentra una justificación para que se produzca tal hecho, impropio desde el pensamiento lógico y desde el sentido común que rige la relación del lector con la realidad. Lo cual nos llevará, como anteriormente se señalaba, a vincular el 'realismo mágico' a una de sus dos manifestaciones posibles, la 'ontológica' o la 'técnica'. Todo es cuestión de paciencia y de desandar un fangoso camino en la búsqueda de iluminación para un término casi centenario.

\section{Bibliografía}

CAMAYD-FreIXAS, E. (1998): Realismo mágico y primitivismo. Relecturas de Carpentier, Asturias, Rulfo y García Márquez. New York - Oxford, University Press of América.

CARpentier, A. (1976): «De lo real maravilloso americano», en Tientos y diferencias. Buenos Aires, Calicanto, pp. 83-99. 
Chanady, A. B. (1985): Magic Realism and the Fantastic: Resolved versus Unresolved Antinomy. New York, Garland.

ChIAMPI, I. (1983): El realismo maravilloso. Forma e ideología en la novela hispanoamericana. Caracas, Monte Ávila.

FLORES, Á. (1955): «El realismo mágico en la narrativa hispanoamericana», Hispania, 38, mayo, pp.187-192. También en Flores (1985), pp.17-24.

- (1985): El realismo mágico en el cuento hispanoamericano. México, Premiá editora.

LEAL, L. (1967): «El realismo mágico en la literatura hispanoamericana», Cuadernos Americanos, CLIII/4, (México, julio-agosto), pp. 230-235.

LlarenA, A. (1997): Realismo Mágico y Lo Real Maravilloso: una cuestión de verosimilitud. Gaithesburg (U.S.A.), Hispamérica.

Menton, S. (1998): Historia verdadera del realismo mágico. México, F.C.E.

Noriega SÁnchez, M. R. (2002): Challenging Realities: Magic Realism in Contemporary American Women's Fiction. Valencia, Universidad de Valencia.

Parkinson Zamora, L. - Wendy, B. F. (1995): Magic Realism: Theory, History, Community. Durham, Duke University Press.

RoAs, D. (2015): «El reverso de lo real: Formas y categorías de lo insólito», en J. ORDIZ, ed., Estrategias y figuraciones de lo insólito en la narrativa mexicana (siglos XIX-XXI). Londres, Peter Lang, pp. 9-30.

RodríGueZ MonegAL, E. (1975): «Realismo mágico versus literatura fantástica: un diálogo de sordos», en D. A. YATES, ed., Otros mundos, otros fuegos. Fantasía y realismo mágico en Iberoamérica. Pittsburg, A Publication of the Latin American Studies Center of Michigan State University, pp. 25-37.

SCHEEL, C. (2005): Réalisme magique et réalisme merveilleux: Des théories aux poétiques. París, L'Harmattan.

USlar PIETRi, A. (1998): «Realismo mágico», en Nuevo mundo, mundo nuevo. Caracas, Biblioteca Ayacucho (versión online en Biblioteca Cervantes), pp. 273-277.

YATES, D. A., ed. (1975): Otros mundos, otros fuegos. Fantasía y realismo mágico en Iberoamérica. Pittsburg, A Publication of the Latin American Studies Center of Michigan State University. 